\title{
Digital models based on images taken with handheld cameras - examples on land, from the sea and on ice
}

\author{
Erik Vest Sørensen, Morten Bjerager and Michele Citterio
}

Geological outcrops can be comfortably modelled in three dimensions in the office using images from a handheld digital camera. Recent developments within the imaging techniques of Structure from Motion (Lowe 2004; Snavely et al. 2008; Fonstad et al. 2013) and photogrammetry (Hirschmüller 2005; James \& Robson 2012; Favalli et al. 2012) have made it easier and cheaper to construct so-called digital outcrop models using stereoscopic images from standard digital cameras. The digital outcrop model (Bellian et al. 2005) is a 3D representation of the outcrop surface and is often displayed in the form of a polygon mesh or a point cloud. In this paper we present three examples of such point clouds from images obtained with a handheld digital camera. The examples illustrate how outcrop topography or digital outcrop models can be constructed at different scales, with different accessibility and operational platforms. Two examples illustrate outcrop

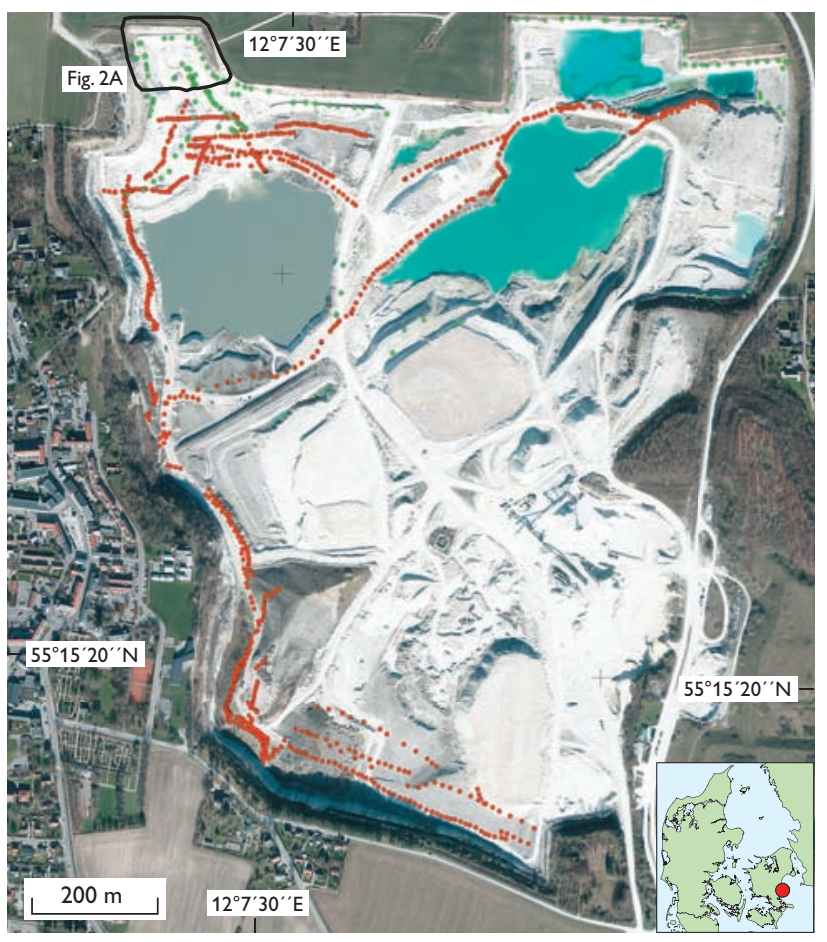

Fig. 1. Overview of the Faxe limestone quarry. Red dots: Images obtained in 2013. Green dots: images obtained in 2014. The inset map shows the location of the Faxe quarry in Denmark. Orthophotograph from Danish Geodata Agency. scales of metres to kilometres, with images obtained by walking along excavated exposures in the Faxe limestone quarry and from a boat sailing past the coastal cliff of Stevns Klint. The third example illustrates detailed micro-topography of ice and snow surfaces where the images were obtained from a snowmobile on an ice cap in A.P. Olsen Land, North-East Greenland.

\section{Methods}

The images were collected with a 36 megapixel Nikon D800E camera equipped with a fixed $35 \mathrm{~mm} \mathrm{f} / 1.4$ Zeiss lens. The camera was locked at infinity in the Faxe quarry and Stevns Klint examples. In the third example from Greenland, the camera was focused and locked so that objects at a distance of $c .2 \mathrm{~m}$ were in focus. The images were recorded with ste-
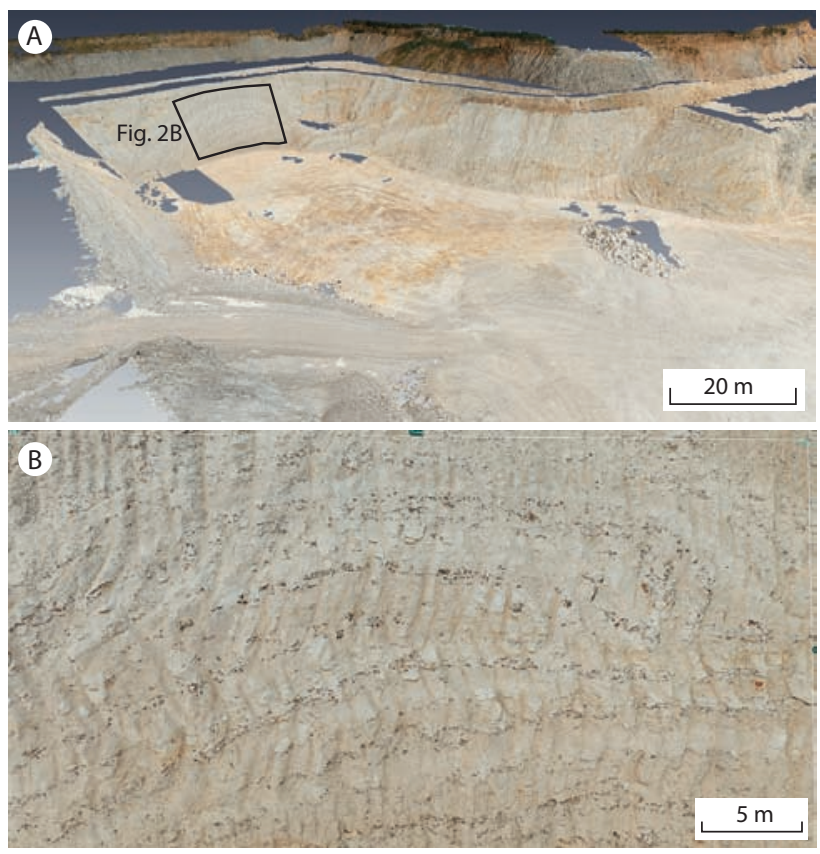

Fig. 2. A: Perspective view (towards the north-east) of the northern part of the Faxe limestone quarry showing the constructed point cloud generated from oblique images obtained in 2014. The point cloud is coloured according to colour value of matched pixels and can be rotated freely in three-dimensions. For location see Fig. 1. B: Close-up of a bryozoan limestone mound with nodular flint layers. 

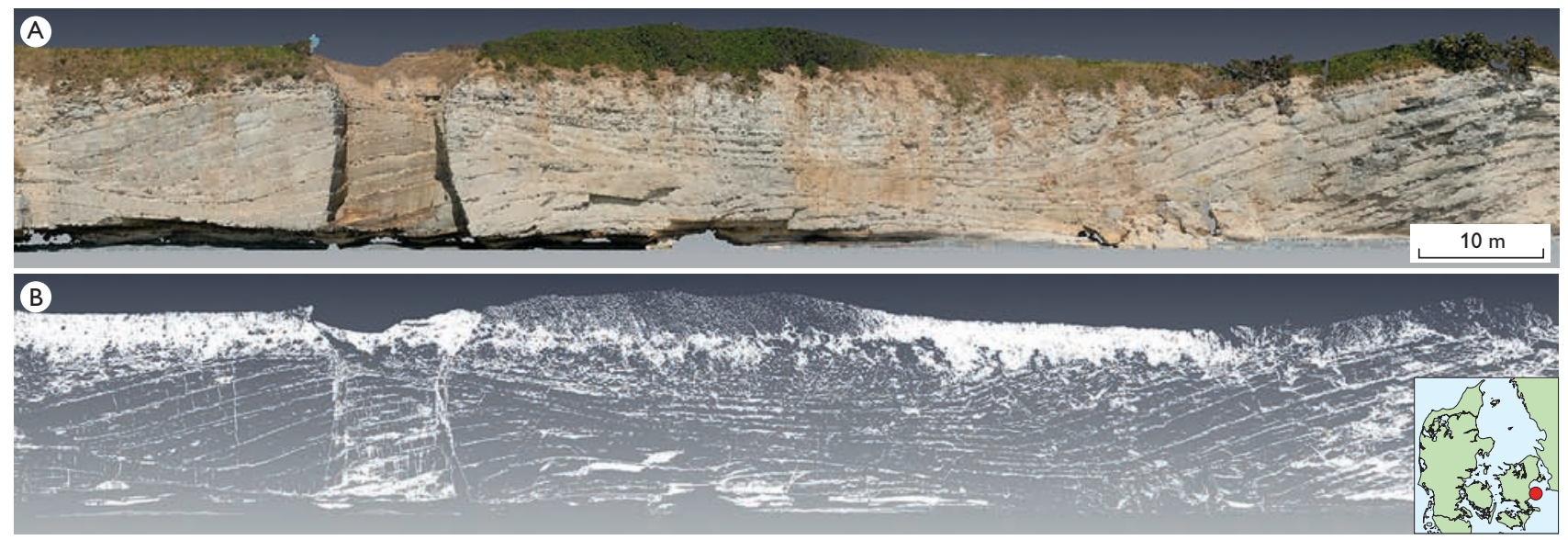

Fig. 3. A: Perspective view of the point cloud generated from a section with Danien bryozoan limestone mounds in the coastal cliff of Stevns Klint. The point cloud is illustrated with RGB-values of matched pixels. B: Perspective view of the filtered point cloud based on colour and surface roughness calculations. The inset map shows the location of Stevns Klint in Denmark.

reoscopic overlaps of up to $90 \%$. In this way image acquisition for digital outcrop models differs from the traditional approach for 3D stereoscopic work (Dueholm 1992), where a stereoscopic overlap of $60-80 \%$ is sufficient to ensure good precision and continuous stereoscopic overlap. Furthermore, images were acquired from much more varied image positions, for example in the Faxe quarry study (Fig. 1), compared with traditional 3D mapping, where images are typically collected along straight parallel lines.

The construction of the digital outcrop models from the images is based on automatic dense multi-view, stereomatching routines. These routines attempt to match each pixel across a range of images. Because of the large overlap, the image baseline is quite small, which decreases the precision of matched pixels. This is, however, compensated for by the redundancy of determining the same point in multiple images. In practice this approach yields a level of precision which is comparable to that typically obtained with stereoimages with $60 \%$ overlap, but with a much better automatic elimination of erroneously matched pixels. This leads to the production of dense point clouds, which require little manual editing, making them well suited for visualisation. The clouds can also be used in morphological analyses. A number of software solutions can generate point clouds from images; in this study we used the professional version of Agisoft PhotoScan and SURE - Photogrammetric Surface Reconstruction from Imagery.

\section{Walking along exposures - the Faxe limestone quarry}

Danian deep-water bryozoan and coral carbonate mounds are exposed in the Faxe limestone quarry (Fig. 1; 55 15'40"N, $12^{\circ} 07^{\prime} 20^{\prime \prime} \mathrm{E}$ ), which represents a perfect case study for $3 \mathrm{D}$ outcrop modelling. The quarry was visited in 2013 and 2014, and a large collection of stereoscopic images documents the changing features of the active quarry. Images of the quarry walls were collected using a handheld digital camera from a distance of $10-20 \mathrm{~m}$, which translates into images with pixel sizes on the ground, also known as the ground sampling distance, in the millimetre range. We used a subset of the data from the northern part of the quarry that is being actively quarried. The result of the reconstruction is a dense point cloud (Fig. 2), which can be freely rotated in 3D and zoomed in on areas of interest. This is a powerful way of visualising geological outcrop data. When combined with a periodic recording of digital images in the active quarry it can provide unique outcrop topographic data sets that make a reconstruction of the $3 \mathrm{D}$ mound topography possible in great detail. It also provides a data set that can be used to quantify volumes of specific characteristic rock types, such as the amount of black-grey nodular flint in the greyish white bryozoan limestone mound systems.

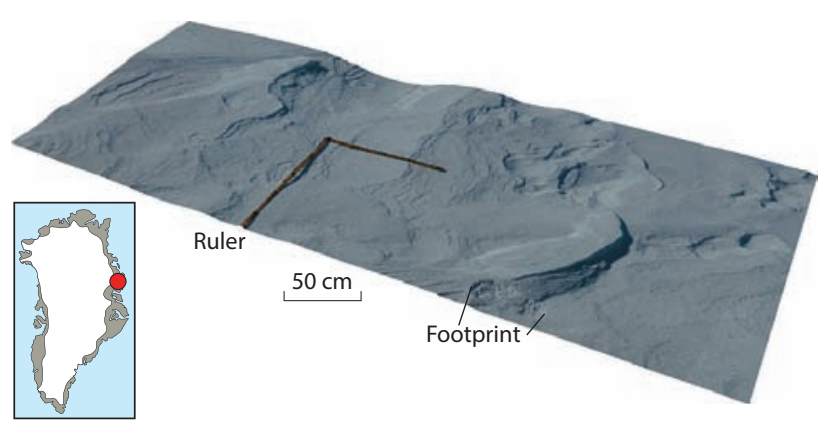

Fig. 4. Perspective view of the reconstructed snow surface measuring 420 $\times 160 \mathrm{~cm}$ from the ice cap in A.P. Olsen Land, North-East Greenland. 

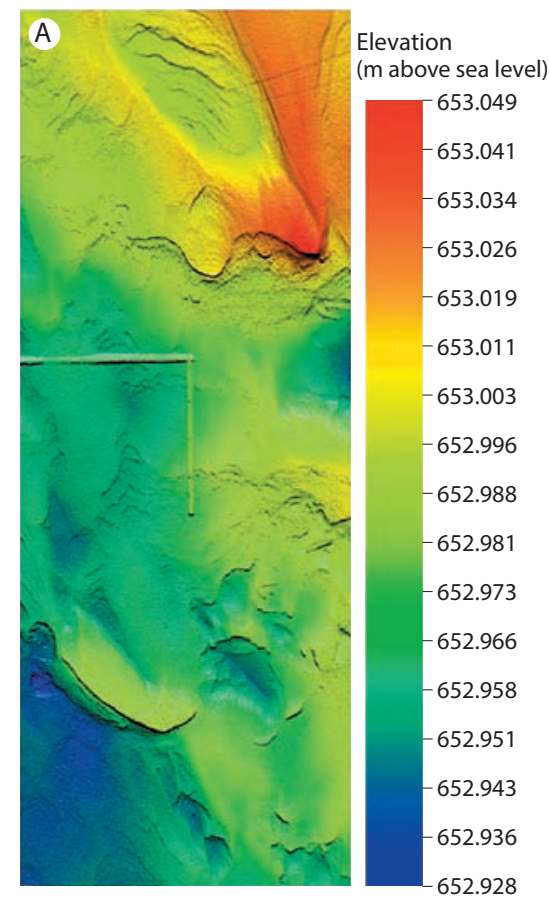

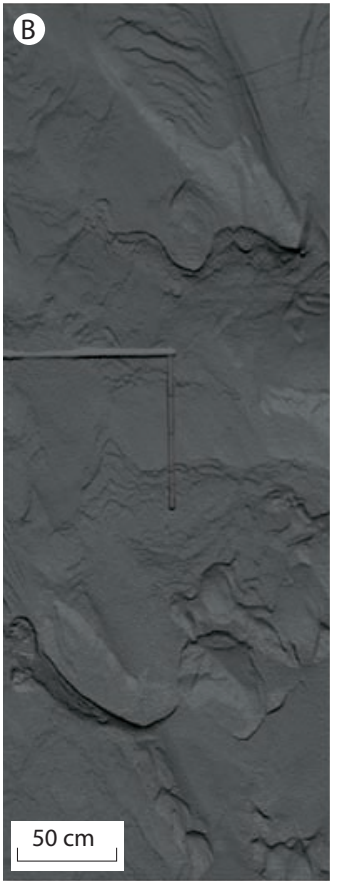

radius $=0.005 \mathrm{~m}$

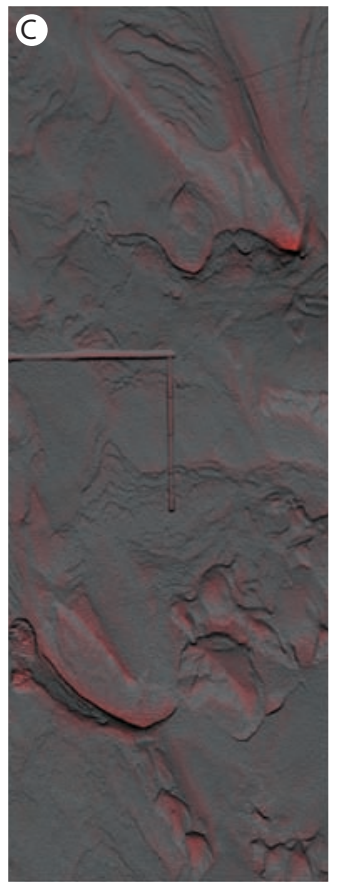

radius $=0.05 \mathrm{~m}$

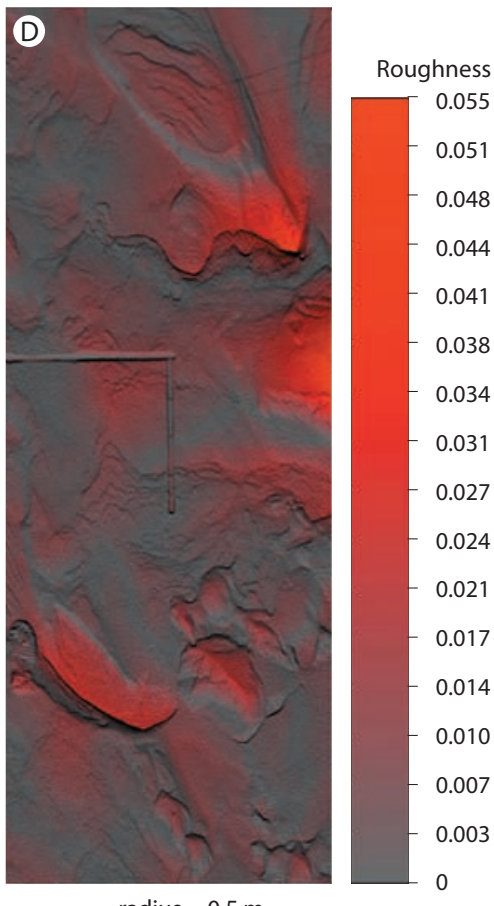

radius $=0.5 \mathrm{~m}$

Fig. 5. Point cloud of the surface shown in Fig. 4, in plane view. A: Coloured according to elevation height. B, C, D: Coloured according to surface roughness. The surface roughness is calculated as the vertical deviation of each point from the best fitted plane defined by data within a sphere with a radius of $0.005 \mathrm{~m}(\mathbf{B}), 0.05 \mathrm{~m}(\mathbf{C})$ and $0.5 \mathrm{~m}(\mathbf{D})$.

\section{Sailing along exposures - Stevns Klint}

Stevns Klint $\left(55^{\circ} 15^{\prime} 39^{\prime \prime} \mathrm{N}, 12^{\circ} 24^{\prime} 52^{\prime \prime} \mathrm{E}\right)$ was recently included in UNESCO's world heritage list and is world famous for its excellent exposure of the Cretaceous-Palaeogene boundary. Images were collected along $11 \mathrm{~km}$ of the coastal cliff from a boat in June 2014, adding new oblique images to the growing archive from previous studies (Surlyk et al. 2006; Pedersen \& Damholt 2012). The images were collected from a distance of 10-300 m, which translates to pixel sizes in the millimetre to centimetre range. This approach allows for high resolution mapping of the mound structures and mega- and mesoscale bedding. Images from a cliff section at Stevnsfortet in the southern part of the cliff were selected to illustrate how simple manipulation of the generated point cloud data (Fig. $3 \mathrm{~A})$ can be used to visualise the overall mound structures. Characteristic black and grey flint nodules follow the internal bedding of the bryozoan mounds and display a strong colour contrast to the light-coloured limestone that can be used to filter away light-coloured points. The resulting point cloud can be analysed with calculations of outcrop parameters such as surface roughness and curvature or, with more sophisticated calculations, used in semi-automatic tracing of discontinuities such as joints, fractures or bedding, developed for terrestrial LiDAR data (Garcia-Sellés et al. 2011).
The result of the filtering is shown in Fig. 3B, which illustrates the structure of the internal bedding in a different way. With little effort this can be extended to include the entire $11 \mathrm{~km}$ surveyed part of the coastal cliff.

\section{Standing on a snowmobile on an ice cap - North-East Greenland}

The third example is from an ice cap in A.P. Olsen Land $\left(74^{\circ} 37^{\prime} 28^{\prime \prime} \mathrm{N}, 21^{\circ} 22^{\prime} 30^{\prime \prime} \mathrm{W}\right)$ in North-East Greenland. The small-scale topography of snow and ice influences the turbulent and radiative components of the surface energy balance, as it controls the aerodynamic roughness length and changes the surface albedo (Munro 1989; Warren et al. 1998; Brock et al. 2006). Surface roughness must also be accounted for in remote sensing of the cryosphere (König et al. 2001). The spatial scales relevant for such applications span several orders of magnitude, with required vertical accuracies in the order of millimetres (Rees \& Arnold 2006). Ground-based photogrammetry appears to be a viable technique to map snow and ice micro-topography in the field down to a scale of centimetres (Irvine-Fynn et al. 2014). Our aim is to demonstrate the feasibility of millimetre-scale accuracy over an outcrop scale of several square metres, under field conditions. 
For this experiment, a person standing on a snowmobile and pointing the camera obliquely downwards collected $29 \mathrm{im}$ ages from different positions. The distance from the camera to the ground was $c .2 \mathrm{~m}$. This approach gives images with a ground sampling distance in the sub-millimetre range. The generated data are a very dense point cloud (Fig. 4). The height of roughness elements per unit length is shown in Fig. 5 over three different spatial wavelengths of $0.005 \mathrm{~m}, 0.05 \mathrm{~m}$ and $0.5 \mathrm{~m}$. This case study shows that it is possible to obtain surface roughness data useful for glaciological and remote sensing applications by relatively simple means.

\section{Summary}

This study demonstrates that it is possible to generate highresolution topographic data at various scales with different accessibility and operational platforms by using a standard digital camera and computer software. The method has a high potential for field geologists, who wish to establish accurate outcrop topographic models that can be 'brought to life' and visualised in 3D surface models. These models can be freely rotated in three dimensions and are well suited for visualisation as well as quantitative purposes in geological mapping. This is an important new addition to the way $3 \mathrm{D}$ mapping is undertaken in the photogrammetry laboratory at the Geological Survey of Denmark and Greenland.

\section{Acknowledgements}

Data from the Faxe limestone quarry and Stevns Klint were obtained with support from Geocenter Denmark and the European Science Foundation COCARDE-ERN.

\section{References}

Bellian, J.A., Kerans, C. \& Jennette, D.C. 2005: Digital outcrop models: applications of terrestrial scanning lidar technology in stratigraphic modeling. Journal of Sedimentary Research 75, 166-176.

Brock, B.W., Willis, I.C. \& Sharp, M.J. 2006: Measurement and parameterization of aerodynamic roughness length variations at Haut Glacier d'Arolla, Switzerland. Journal of Glaciology 52, 281-297.
Dueholm, K.S. 1992: Geologic photogrammetry using standard smallframe cameras. Rapport Grønlands Geologiske Undersøgelse 156, 7-17.

Favalli, M., Fornaciai, A., Isola, I., Tarquini, S. \& Nannipieri, L. 2012: Multiview 3D reconstruction in geosciences. Computers \& Geosciences 44, 168-176.

Fonstad, M.A., Dietrich, J.T., Courville, B.C., Jensen, J.L. \& Carbonneau, P.E. 2013: Topographic structure from motion: a new development in photogrammetric measurement. Earth Surface Processes and Landforms 38, 421-430.

García-Sellés, D., Falivene, O., Arbués, P., Gratacos, O., Tavani, S. \& Muñoz, J.A. 2011: Supervised identification and reconstruction of nearplanar geological surfaces from terrestrial laser scanning. Computers \& Geosciences 37, 1584-1594.

Hirschmüller, H. 2005: Accurate and efficient stereo processing by semiglobal matching and mutual information. In: Schmid, C., Soatto, S. \& Tomasi, C. (eds): Proceedings of IEEE Conference on Computer Vision and Pattern Recognition (CVPR), San Diego, CA, USA, 20-26 June 2005, 2, 807-814.

Irvine-Fynn, T.D.L., Sanz-Ablanedo, E., Rutter, N., Smith, M.W. \& Chandler, J.H. 2014: Instruments and methods. Measuring glacier surface roughness using plot-scale, close-range digital photogrammetry. Journal of Glaciology 60, 957-969.

James, M.R. \& Robson, S. 2012: Straightforward reconstruction of 3D surfaces and topography with a camera: accuracy and geoscience application. Journal of Geophysical Research 117(F3), F03017.

König, M., Winther, J.G. \& Isaksson, E. 2001: Measuring snow and glacier ice properties from satellite. Reviews of Geophysics 39, 1-27.

Lowe, D.G. 2004: Distinctive image features from scale-invariant key points. International Journal of Computer Vision 60, 91-110.

Munro, S. 1989: Surface roughness and bulk heat transfer on a glacier: comparison with eddy correlation. Journal of Glaciology 35, 343-348.

Pedersen, S.A.S. \& Damholt, T. 2012: Cliff collapse at Stevns Klint, south-east Denmark. Geological Survey of Denmark and Greenland Bulletin 26, 33-36.

Rees, W.G. \& Arnold, N.S. 2006: Scale-dependent roughness of a glacier surface: implications for radar backscatter and aerodynamic roughness modelling. Journal of Glaciology 52, 214-222.

Snavely, N., Seitz, S. \& Szeliski, R. 2008: Modeling the World from internet photo collections. International Journal of Computer Vision 80, 189-210.

Surlyk, F., Damholt, T. \& Bjerager, M. 2006: Stevns Klint, Denmark: uppermost Maastrichtian chalk, Cretaceous-Tertiary boundary, and lower Danian bryozoan mound complex. Bulletin of the Geological Society of Denmark 54, 1-48.

Warren, S.G., Brandt, R.E. \& Hinton, O.P. 1998: Effect of surface roughness on bidirectional reflectance of Antarctic snow. Journal of Geophysical Research 103(E11), 25789-25805.

\footnotetext{
Authorshddress

Geological Survey of Denmark and Greenland, Øster Voldgade 10, DK-1350 Copenhagen K, Denmark. E-mail address:evs@geus.dk
} 